\title{
Incidence of cataract operations in Finnish male smokers unaffected by $\alpha$ tocopherol or $\beta$ carotene supplements
}

\author{
J M Teikari, M Rautalahti, J Haukka, P Järvinen, A M Hartman, J Virtamo, D Albanes, \\ O Heinonen
}

\begin{abstract}
Objective-To examine the effect of $\alpha$ tocopherol and $\beta$ carotene supplementation on the incidence of age related cataract extraction.

Setting-The Alpha-tocopherol Betacarotene (ATBC) Study was a randomised, double blind, placebo controlled, $2 \times 2$ factorial trial conducted in south western Finland. The cataract surgery study population of 28934 male smokers 50-69 years of age at the start.

Intervention-Random assignment to one of four regimens: $\alpha$ tocopherol $50 \mathrm{mg}$ per day, $\beta$ carotene $20 \mathrm{mg}$ per day, both $\alpha$ tocopherol and $\beta$ carotene, or placebo. Follow up continued for five to eight years (median 5.7 years) with a total of 159199
\end{abstract} person years.

Outcome measure-Cataract extraction, ascertained from the National Hospital Discharge Registry.

Results-425 men had cataract surgery because of senile or presenile cataract during the follow up. Of these, 112 men were in the $\alpha$ tocopherol alone group, 112 men in the $\beta$ carotene alone group, 96 men in the $\alpha$ tocopherol and $\beta$ carotene group, and 105 men in the placebo group. When supplementation with $\alpha$ tocopherol and with $\beta$ carotene were introduced to a Cox proportional hazards model with baseline characteristics (age, education, history of diabetes, body mass index, alcohol consumption, number of cigarettes smoked daily, smoking duration, visual acuity, and total cholesterol), neither $\alpha$ tocopherol (relative risk, RR, $0.91,95 \%$ confidence intervals, CI, $0.74,1.11$ ) nor $\beta$ carotene (RR 0.97, 95\% CI 0.79, 1.19) supplementation affected the incidence of cataract surgery.

Conclusion-Supplementation with $\alpha$ tocopherol or $\beta$ carotene does not affect the incidence of cataract extractions among male smokers.

(F Epidemiol Community Health 1998;52:468-472)

National Cancer Institute, Nationa Institute of Health, Maryland, USA

A M Hartman

D Albanes

Correspondence to: Dr J Teikari, PL39, 00551, Helsinki, Finland.

Accepted for publication 23 October 1997 overprovision of certain vitamins and micronutrients can affect the development cataract. ${ }^{1-6}$ Several observational studies in humans have shown an inverse association between cataract development and multivitamin supplementation, ${ }^{7}$ vitamin $\mathrm{E}$ or $\mathrm{C}$ supplementation, ${ }^{8}$ and high plasma concentra-
Animal studies have shown that deprivation or tions of vitamin $\mathrm{E}$, vitamin $\mathrm{C}$ or carotenoids ${ }^{9-11}$ while other studies have observed no association. ${ }^{12}$ Two double masked controlled clinical trials have been carried out in China to examine the effect of vitamin and mineral supplements on the prevalence of end of trial cataract. In one the combination of $\beta$ carotene, vitamin $\mathrm{E}$, and selenium had no effect on the prevalence whereas in the other multisupplementation with 26 vitamins and minerals including $\beta$ carotene and vitamin $\mathrm{E}$ reduced the prevalence among persons aged 65 to 74 years. $^{13}$

Incidence of cataract is strongly associated with age. ${ }^{14}$ Various manifestations and diseases of aging are believed to be caused by oxidative damage to tissues ${ }^{15}$ mediated by free radicals. In humans complex antioxidative systems protect against this oxidative damage. ${ }^{16}$

We present the incidence of age related cataract extractions in the Alpha-tocopherol, Betacarotene Study (ATBC Study), which was originally designed to study the possible protective effect of $\alpha$ tocopherol or $\beta$ carotene on the incidence of lung cancer. The study was a joint project of the National Public Health Institute of Finland and the US National Cancer Institute.

Methods in ATBC study

STUDY DESIGN AND POPULATION

Detailed information on study design, methods, randomisation, characteristics of participants, measures of compliance, and overall conduct of the study has been published earlier. ${ }^{17}$ The participants $(n=29133)$ were recruited in 1985-1988 from the entire male population aged 51-69 years of 14 geographical areas in south western Finland. They were respondents to a postal survey $(n=224$ 377) to find eligible participants: smokers of at least five cigarettes per day, and willing to give informed written consent. Before enrollment in the study, potential participants were interviewed by a nurse at one of the 14 local study centres to obtain background information and further evaluate their eligibility. A chest radiograph was taken to exclude prevalent lung cancer cases. Men with a history of cancer or serious disease limiting their ability to participate, taking supplements of vitamin $\mathrm{E}$, vitamin $\mathrm{A}$, or $\beta$ carotene in excess of predefined doses, or being treated with anticoagulants, were also excluded. At baseline, dietary intakes of $\alpha$ tocopherol and $\beta$ carotene were estimated from the diet history questionnaire, ${ }^{18}$ and height, 
Table 1 Baseline characteristics (median or per cent of total) of the ATBC cataract surgery study population by intervention category

\begin{tabular}{|c|c|c|c|c|}
\hline Characteristic & $A T$ & $A T B C$ & $B C$ & Placebo \\
\hline Number of subjects & 7230 & 7227 & 7237 & 7240 \\
\hline Age (y) & 57.1 & 57.3 & 57.2 & 56.9 \\
\hline Cigarettes/day & 20.0 & 20.0 & 20.0 & 20.0 \\
\hline Years of smoking & 36.0 & 36.0 & 37.0 & 36.0 \\
\hline Serum cholesterol $(\mathrm{mmol} / \mathrm{l})$ & 6.15 & 6.18 & 6.15 & 6.15 \\
\hline Body mass index $\left(\mathrm{kg} / \mathrm{m}^{2}\right)$ & 26.0 & 26.0 & 25.9 & 26.0 \\
\hline Diabetes (self reported, \%) & 4.1 & 4.6 & 4.5 & 3.8 \\
\hline Hypertension (self reported, \%) & 29.3 & 29.9 & 29.6 & 28.3 \\
\hline Education (over 9 years, \%) & 22.8 & 24.1 & 22.9 & 23.2 \\
\hline Alcohol (g/day) & 11.3 & 10.8 & 11.0 & 10.8 \\
\hline \multicolumn{5}{|l|}{ Serum } \\
\hline$\alpha$ tocopherol $(\mathrm{mg} / \mathrm{l})$ & 11.5 & 11.6 & 11.5 & 11.5 \\
\hline$\beta$ carotene $(\mu \mathrm{g} / \mathrm{l})$ & 168.0 & 172.0 & 170.0 & 172.0 \\
\hline \multicolumn{5}{|l|}{ Dietary } \\
\hline vitamin $\mathrm{E}$ (mg/day) & 10.2 & 10.3 & 10.3 & 10.2 \\
\hline$\beta$ carotene (mg/day) & 1.64 & 1.68 & 1.65 & 1.67 \\
\hline \multicolumn{5}{|l|}{ Visual acuity ${ }^{\star}$} \\
\hline \multicolumn{5}{|l|}{ without glasses } \\
\hline right eye & 0.6 & 0.6 & 0.7 & 0.7 \\
\hline left eye & 0.7 & 0.7 & 0.7 & 0.7 \\
\hline \multicolumn{5}{|l|}{ with glasses } \\
\hline right eye & 1.0 & 1.0 & 1.0 & 1.0 \\
\hline left eye & 1.0 & 1.0 & 1.0 & 1.0 \\
\hline
\end{tabular}

$\overline{\mathrm{AT}}=\alpha$ tocopherol alone. $\mathrm{ATBC}=\alpha$ tocopherol and $\beta$ carotene. $\mathrm{BC}=\beta$ carotene alone. ${ }^{\star}$ Visual acuity measured with Snellen charts.

weight, and blood pressure measured. Visual acuity was measured using the Snellen visual acuity charts without and with the possible glasses for far vision. A blood sample was drawn and serum deep frozen from which total cholesterol, $\alpha$ tocopherol, and $\beta$ carotene values were later measured.

The ATBC Study was approved by the review boards of the participating institutions, and a data and safety monitoring committee was convened twice annually throughout the study to evaluate unblinded data relevant to safety and efficacy.

RANDOMISATION

A two by two factorial design permitted the study of the effects of two different supplements in one trial. Eligible participants were randomly (in blocks of eight within each of the 14 study areas) assigned to one of the four intervention categories: $\alpha$ tocopherol $50 \mathrm{mg} /$ day $(\mathrm{n}=7286), \quad \beta$ carotene $20 \mathrm{mg} /$ day $(\mathrm{n}=7282)$, a combination of the two $(\mathrm{n}=7278)$, and placebo $(n=7287)$. As a result, half of the participants received $\alpha$ tocopherol $(n=14564)$ and half did not $(n=14569)$, while half

Table 2 Number and incidence of cataract extraction in the ATBC study by age (at baseline)

\begin{tabular}{lllll}
\hline Age group $(y)$ & Number & $\begin{array}{l}\text { Incidence } / 1000 \text { person } \\
\text { years }\end{array}$ & Relative risk & 95\% CI \\
\hline $50-55$ & 61 & 2.0 & 1.0 & \\
$56-60$ & 110 & 4.0 & 2.0 & $1.5,2.7$ \\
$61-65$ & 136 & 7.8 & 3.9 & $2.9,5.2$ \\
$66-$ & 118 & 15.6 & 7.8 & $5.7,10.6$ \\
\hline
\end{tabular}

Table 3 Incidence per 1000 person years of cataract extractions in the tertiles of baseline dietary intakes and serum concentrations of vitamin E/a tocopherol and $\beta$ carotene among the placebo group participants of the ATBC study. Relative risks and $95 \%$ confidence intervals are shown for comparisons with lowest tertile (shown in parentheses)

\begin{tabular}{llll}
\hline & \multicolumn{2}{l}{ Incidence per 1000 person years } \\
\cline { 2 - 4 } & Lowest tertile & Middle tertile & Highest tertile \\
\hline Dietary vitamin E & $3.03(1.0)$ & $2.61(0.90 .7,1.1)$ & $2.37(0.80 .6,1.0)$ \\
Dietary $\beta$ carotene & $3.13(1.0)$ & $2.66(0.80 .7,1.1)$ & $2.22(0.70 .6,0.9)$ \\
Serum $\alpha$ tocopherol & $3.18(1.0)$ & $2.33(0.70 .6,0.9)$ & $2.53(0.80 .6,1.0)$ \\
Serum $\beta$ carotene & $3.00(1.0)$ & $2.87(1.00 .8,1.2)$ & $2.15(0.70 .6,0.9)$ \\
\hline
\end{tabular}

received $\beta$ carotene $(n=14560)$ and half did not $(n=14$ 573). The dose of $\alpha$ tocopherol was approximately five times and the dose of $\beta$ carotene three times the recommended daily intake.

SUPPLEMENT DELIVERY AND BLINDING

Capsules contained synthetic dl- $\alpha$-tocopheryl acetate (50 per cent powder) or synthetic $\beta$ carotene (10 per cent water soluble beadlets), or both. They were packed in coded blister pack wallets in calendar format, from which one capsule was to be taken daily. The participants made a follow up visit to their study centre three times a year, when a new individual pack was dispensed. Compliance was monitored by counts of the remaining capsules at each visit. Capsule compliance was excellent, with four of five active (participants coming to follow up visits) participants taking more than 95 per cent of their capsules and there were no differences in the capsule consumption among the intervention groups.

All study participants and personnel remained masked as to the intervention assignment of each individual participant throughout the trial. Persistent yellowing of the skin (during two thirds or more of the follow up periods) was reported by $8.8 \%$ of those taking $\beta$ carotene, compared with $0.3 \%$ of those who did not. ${ }^{19}$

END POINT ASSESSMENT IN CATARACT STUDY

The end point of this study was cataract surgery. Cases of surgery were identified retrospectively through the nationwide Hospital Discharge Register that covers all public and private hospitals performing cataract surgeries in Finland. This registry was available for the years 1984 to 1992 . The register linkage was based on the use of unique Finnish personal identification number. Hospital admissions of men with cataract were first identified using the International Classification of Diseases (ICD) codes for presenile (ICD 8th edition code 374,01 until the end of 1986 and ICD 9th code 3660C thereafter) and senile cataracts (ICD 8th code 374,02 and ICD 9th code 3661A). Thereafter possible cataract surgery was checked from the surgery codes including extracapsular extraction of a nuclear cataract, extracapsular cataract extraction and implantation of an intraocular lens (IOL), intracapsular cataract extraction, intracapsular cataract extraction and implantation of an IOL, and implantation of an IOL.

If a cataract operation had been performed before enrollment to the ATBC study in either eye, the case was excluded $(n=199)$. They were equally distributed among the four intervention groups. Only the first discharge with cataract surgery during the follow up was accepted as an end point and possible later discharges with cataract surgery (fellow eye, re-operation, etc) were not considered. Follow up of the cataract study ranged from five to eight years (median 5.7 years), until death, hospital admission because cataract operation or 31 December 1992, with a total of 159199 person 
Table 4 Number and incidence (per 1000 person years) of cataract extractions by intervention group. Relative risks and $95 \%$ confidence intervals are given for comparison with placebo)

\begin{tabular}{lcl}
\hline Intervention group & $\begin{array}{l}\text { Number with } \\
\text { cataract surgery }\end{array}$ & Incidence $(95 \%$ CI) \\
\hline$\alpha$ tocopherol alone & 112 & $2.82(1.070 .82,1.40)$ \\
$\alpha$ tocopherol and $\beta$ & & $2.42(0.920 .70,1.21)$ \\
$\quad$ carotene & 96 & $2.82(1.070 .82,1.40)$ \\
$\beta$ catorene alone & 112 & $2.63(1.00)$ \\
Placebo & 105 & \\
\hline
\end{tabular}

years. There were altogether 28934 participants at the start of intervention in this study.

A total of 425 men with cataract surgery during follow up were found. Of these, 52 men (12 per cent) had the procedure because of presenile cataract and 373 men ( 88 per cent) because of senile cataract. The most common procedure, in 96 per cent of the operations, was extracapsular cataract extraction and implantation of an intraocular lens.

STATISTICAL ANALYSES

Statistical analyses focused on estimating the effect of the two supplements on cataract extraction. The intention to treat principle was used and thus follow up and case ascertainment continued even when a participant dropped out of the study. Interaction between the two supplements was estimated using the proportional hazards model. ${ }^{20}$ Kaplan-Meier curves were constructed for cumulative incidences of cataract surgeries separately for $\alpha$ tocopherol compared with no $\alpha$ tocopherol,

Table 5 Relative risk (RR) and confidence intervals (CI) for cataract extraction obtained from a Cox proportional hazards model for supplementation with a tocopherol and $\beta$ carotene and baseline risk factors for cataract

\begin{tabular}{|c|c|c|}
\hline Risk factor & $R R$ & $95 \% C I$ \\
\hline Supplementation with $\alpha$ tocopherol (yes/no) & 0.91 & $0.74,1.11$ \\
\hline Supplementation with $\beta$ carotene (yes/no) & 0.97 & $0.79,1.19$ \\
\hline \multicolumn{3}{|l|}{ Age (y) } \\
\hline-55 & 1.00 & \\
\hline $56-60$ & 1.61 & $1.14,2.28$ \\
\hline $61-65$ & 2.81 & $1.95,4.04$ \\
\hline & 4.81 & $3.28,7.06$ \\
\hline \multicolumn{3}{|l|}{ Total education (y) } \\
\hline-8 & 1.00 & \\
\hline $9-12$ & 1.38 & $1.03,1.85$ \\
\hline $13-$ & 2.27 & $1.59,3.23$ \\
\hline History of diabetes (yes/no) & 1.82 & $1.24,2.66$ \\
\hline History of hypertension (yes/no) & 1.00 & $0.81,1.24$ \\
\hline \multicolumn{3}{|l|}{ Body mass index $\left(\mathrm{kg} / \mathrm{m}^{2}\right)$} \\
\hline-24.4 & 1.00 & \\
\hline $24.5-27.6$ & 1.24 & $0.96,1.59$ \\
\hline $27.7-$ & 1.41 & $1.09,1.82$ \\
\hline \multicolumn{3}{|l|}{ Alcohol (g/day) } \\
\hline abstainers & 1.00 & \\
\hline $1-30$ & 1.15 & $0.82,1.59$ \\
\hline $31-60$ & 1.47 & $0.98,2.21$ \\
\hline $61-$ & 1.86 & $1.13,3.06$ \\
\hline \multicolumn{3}{|l|}{ Duration of smoking (y) } \\
\hline-34 & 1.00 & \\
\hline $35-$ & 1.16 & $0.89,1.51$ \\
\hline \multicolumn{3}{|l|}{ Cigarettes smoked/day } \\
\hline-14 & 1.00 & \\
\hline $15-29$ & 1.03 & $0.80,1.32$ \\
\hline $30-$ & 0.89 & $0.63,1.26$ \\
\hline \multicolumn{3}{|l|}{ Serum cholesterol $(\mathrm{mmol} / \mathrm{l})$} \\
\hline-5.6 & 1.00 & \\
\hline $5.7-6.7$ & 0.73 & $0.56,0.95$ \\
\hline $6.8-$ & 0.86 & $0.65,1.15$ \\
\hline \multicolumn{3}{|l|}{ Visual acuity } \\
\hline-0.32 & 1.00 & \\
\hline $0.33-0.66$ & 0.25 & $0.19,0.32$ \\
\hline $0.67-$ & 0.10 & $0.08,0.13$ \\
\hline
\end{tabular}

$\star V$ isual acuity in the worse eye with possible glasses. If no glasses worn, visual acuity of the worse eye without glasses. and for $\beta$ carotene with no $\beta$ carotene supplements. ${ }^{21}$ Two sided nominal $p$ values were derived from the unweighted log rank statistics. ${ }^{20}$ Cox proportional hazards model was constructed with the time vector as the interval between randomisation and day of hospital admission fo a cataract surgery.

\section{Results}

At study entry, there were no differences in the possible risk factors of cataract (table 1) among the intervention groups. Stopping smoking during the trial was similar in the intervention groups ranging from 8.9 per cent ( $\alpha$ tocopherol and $\beta$ carotene alone) to 9.3 per cent (both $\alpha$ tocopherol and $\beta$ carotene). Also the proportion of participants leaving the study for any reason, including death, did not differ between the intervention groups ranging from 28.4 per cent ( $\alpha$ tocopherol alone) to 29.4 per cent ( $\beta$ carotene alone).

A total of 425 men had cataract surgery because of senile or presenile cataract during follow up. The incidence of cataract surgery rose rapidly with age (table 2 ).

The placebo group $(n=7240)$ was divided into tertiles with regard to the baseline dietary intakes and serum concentrations of vitamin $\mathrm{E}, \alpha$ tocopherol, and $\beta$ carotene. The incidence of cataract extraction was similar in each tertile of serum $\alpha$ tocopherol, dietary vitamin $\mathrm{E}$, and dietary $\beta$ carotene. High baseline serum $\beta$ carotene was suggestive of a lower risk of cataract extraction (table 3 ).
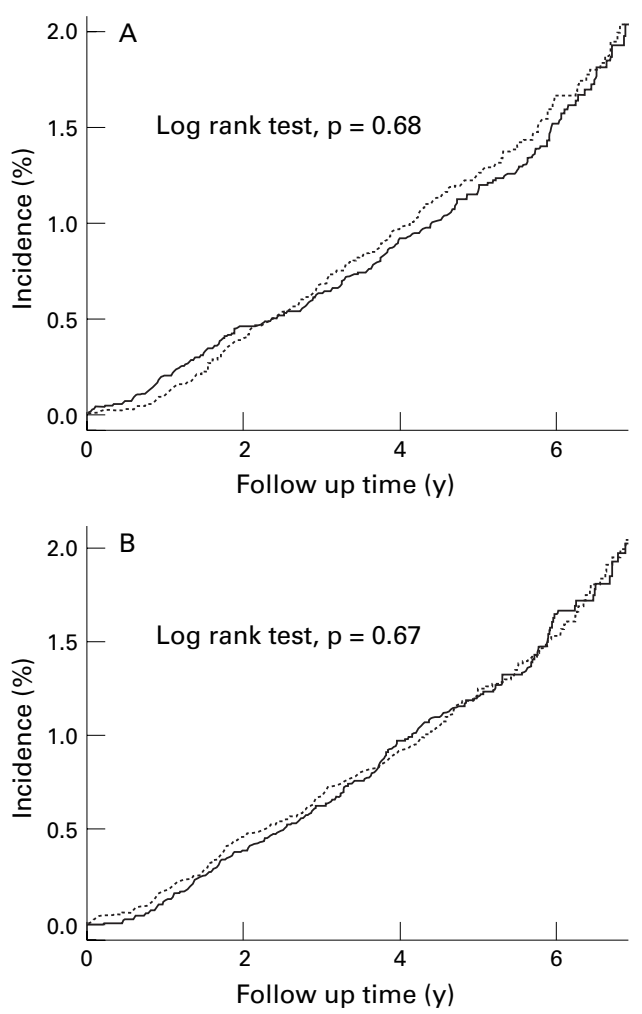

Figure 1 (A) Kaplan-Meier curves for the cumulative incidence of cataract surgery among participants receiving a tocopherol (solid line) supplements or not (dotted line) and (B) among participants receiving $\beta$ carotene (solid line) supplements or not (dotted line) in the lower panel. The steps in lines are 100 day periods of observation. 
The numbers of cataract extractions were highest in the $\alpha$ tocopherol and $\beta$ carotene groups being $112(1.6 \%)$ in $\alpha$ tocopherol and $112(1.5 \%)$ in $\beta$ carotene groups. The numbers were lowest in the combined supplementation group $(96(1.3 \%))$, with the placebo group in the middle $(105(1.4 \%)$ ) (table 4$)$.

No interaction was observed between $\alpha$ tocopherol and $\beta$ carotene supplementation in their effect on incidence of cataract extraction $(p=0.3)$. The cumulative incidences of cataract extraction were similar among men who received $\alpha$ tocopherol or $\beta$ carotene compared with the men not receiving $\alpha$ tocopherol or $\beta$ carotene, respectively (fig 1 ). When $\alpha$ tocopherol and $\beta$ carotene supplementation was introduced into the Cox proportional hazards model together with the risk factors for cataract, neither $\alpha$ tocopherol (RR 0.91, 95\% CI $0.74,1.11$ ) nor $\beta$ carotene (RR $0.97,95 \%$ CI $0.79,1.19)$ supplementation affected the incidence of cataract extraction (table 5). High age, history of diabetes, high body mass index, low baseline visual acuity, longer education, and moderate to heavy use of alcohol increased the risk of a cataract surgery significantly. No interaction was found between the supplementation with $\alpha$ tocopherol or $\beta$ carotene and the risk factors for cataract extraction.

\section{Discussion}

Our results that $\alpha$ tocopherol or $\beta$ carotene supplementation has no effect on the incidence of cataract extraction conflicts with findings from many observational studies showing a protective effect of antioxidants on cataract. Unadjusted confounding with unmeasured risk factors for cataract is however a major concern in observational studies. Randomisation in a controlled trial should balance the unknown confounding factors evenly across the supplementation groups.

Two placebo controlled clinical trials have so far been published on antioxidant supplementation in the prevention of age related cataract. ${ }^{13}$ These studies were performed in regions of China with very low intake of some vitamins. In the first population a protective effect of supplementation with 26 vitamins and minerals on nuclear cataract was noted in the 65-74 year age group. The supplementation included $\beta$ carotene (15 mg/day) and $\alpha$ tocopherol (60 IU/day). However, no association was observed when the whole age range of 45-74 years was analysed. In the second population the combination of riboflavin ( $3 \mathrm{mg} /$ day) and niacin ( $40 \mathrm{mg} /$ day) showed a protective effect again only among the 65-74 year olds, but the combination of selenium $(50 \mu \mathrm{g} /$ day $), \alpha$ tocopherol (30 mg/day) and $\beta$ carotene (15 $\mathrm{mg}$ /day) did not influence the risk of cataract.

The true cataract status in our sample at the start of the intervention is not known. Visual acuity can be used as a surrogate for cataract severity; it was similar with and without glasses in the intervention groups at baseline. If imbalance in cataract status had existed as a result of incomplete randomisation, a difference in visual acuity between the groups would be expected. All risk factors for cataract were evenly distributed in the intervention groups at baseline. Thus the distribution of subclinical cataracts was most probably equal in the intervention groups at the start. Length of education differed between the intervention groups at baseline-total years of education was significantly higher in the combination group, but more or less equal in the $\alpha$ tocopherol alone, $\beta$ carotene alone, and placebo groups. This imbalance may be considered to be a result of chance.

All participants in the ATBC study were current smokers at the start of the study. A total of 6131 participants stopped smoking during the follow up, and they were equally distributed across all intervention categories. Previous studies have suggested that the protective effect of carotenoids is present in non-smokers but not smokers. ${ }^{22}$ Duration of smoking was used as a covariate in our study. No effect modification was noted and the average duration of smoking was equal across the intervention groups.

Diabetes is a known risk factor for cataract, ${ }^{23}$ and it increased the risk of cataract extraction in this study. There did not, however, seem to be any effect in analyses when adjusting for diabetes in the Cox models. There were fewer participants with diabetes in the placebo group than in the other intervention groups at baseline, though the difference was not statistically significant. This imbalance in randomisation could have diluted the possible effect of the antioxidants in preventing cataract development.

Alcohol consumption was associated with an increased risk of cataract extraction in our sample, an association previously recognised. ${ }^{24}$ Similar but borderline significance in cataract extraction risk was noticed with increasing body mass index. The increase in cataract extraction risk with more education is in contrast with findings from previous studies. $^{1223}$

Cataract surgery as an end point excludes cases, in which cataract is present but the operation not performed for some reason. Our method of case ascertainment identifies the most severe cases of cataract, and there is no plausible reason for it to have biased the ascertainment of cases differently across the intervention groups. The incidence of cataract was lower than in studies where cataract status has been determined by clinical measurement of lens opacity. ${ }^{13}$ On the other hand the incidence was increased by studying only smokers, who are known to be at risk for cataract. ${ }^{22}{ }^{25}$ The three major cataract types: nuclear sclerosis, cortical cataract, and posterior subcapsular cataract, may not have been represented in the same proportions in our material as reported in the literature. ICD classification does not differentiate the cataract subtypes. Posterior subcapsular cataract is known to affect visual performance the most, and surgery becomes necessary at an early phase of the disease. Nuclear cataract has been proposed to benefit most from the antioxidant vitamins. ${ }^{1323}$

The Hospital Discharge Registry may be considered a comprehensive and accurate 
source of information on cataract extractions, and all hospitals performing cataract surgeries in Finland are covered by it. The Registry's validity has been tested for stroke and myocardial infarction, ${ }^{26}$ alcohol related disorders, ${ }^{27}$ and acute angle closure glaucoma ${ }^{28}$; the validity of first diagnosis was $81.2 \%$ for stroke, $84.7 \%$ for myocardial infarction, and $91 \%$ for five alcohol related disorders. In the third study mentioned above the authors found a validity of $80 \%$ for acute angle closure glaucoma in the Registry in a re-examination of 172 patient files.

Incidence of cataract surgery was lower (3.90 per 1000 person years) among those men with high serum $\beta$ carotene (highest tertile) at baseline compared with those with low concentration (lowest tertile) of serum $\beta$ carotene (5.97 per 1000 person years). Previous studies have shown a lower incidence of cataract surgeries among persons with higher serum concentrations of $\alpha$ tocopherol. ${ }^{11}$ No such trend was present with serum $\alpha$ tocopherol in this study.

The duration of intervention, doses of study agents, and inappropriate choice of study agents are possible reasons for the disparity between our results and those of earlier studies. The development of a cataract is a long process. The median follow up in this study was 6.1 years, which is long enough for a senile cataract to progress significantly in this age group. ${ }^{29}$ If a favourable effect of antioxidants does exist, some or most of that effect should have emerged during our intervention. The doses of $\alpha$ tocopherol and $\beta$ carotene in the ATBC study exceeded the dietary intakes demonstrating a protective effect in previous observational studies. $^{22}$ Some authors have suggested that carotenoids other than $\beta$ carotene are responsible for the protective effect in age related cataract. ${ }^{22}$

Cataract surgery is an imprecise indicator of cataract, and especially of different cataract subtypes treated with surgery. Moreover the effects of antioxidants may vary across cataract subtypes. More observational studies and controlled trials are thus called for to elucidate the significance of antioxidants in the development of cataract.

This study was supported by the Juho Vainio Foundation, Helsinki, Finland. The ATBC study was supported by Public Health Service Contract N01-CN-45165 from the Division of Cancer Prevention and Control, National Cancer Institute of the United States.

1 Trevithick JR, Creighton MO, Ross WM, et al. Modelling cortical cataractogenesis: 2 . In vitro effects on the lens of agents preventing glucose- and sorbitol-induced cataracts. Can f Ophthalmol 1981;16:32-8.
2 Varma SD, Beachy NA, Richards RD. Photoperoxidation of lens lipids: prevention by vitamin E. Photochem Photobiol 1982;36:623-6.

3 Ross WM, Creighton MO, Inch WR, et al. Radiation cataract formation diminished by vitamin $\mathrm{E}$ in rat lenses in vitro. Exp Eye Res 1983;36:645-53.

4 Gupta PP, Pandey DJ, Sharma AL, et al. Prevention of experimental cataract by alpha tocopherol. Indian 7 Exp Biol 1984;22:620-2.

5 Bunce GE, Kinoshita J, Horwitz J. Nutritional factors in cataract. Anпu Rev Nutr 1990;10:233-54.

6 Taylor A. Associations between nutrition and cataract. Nutr Rev 1989;47:225-34

7 Leske MC, Chylack LT, Wu SY, LOCS research Group. other risk factors. Invest Ophthalmol Vis Sci 1990:31:374.

8 Robertson JM, Donner AP, Trevithick JR. Vitamin E intake and risk of cataracts in humans. Ann N Y Acad Sci 1990;503:372-82.

9 Jaques PF, Chylack LT, McGandy RB, et al. Antioxidant status in persons with and without senile cataract. Arch Ophthalmol 1988;106:337-40

10 Mohan M, Sperduto RD, Angra SK, et al. India-US case-control study of age-related cataracts. Arch Ophthalmol 1989;107:670-6.

11 Knekt P, Heliövaara M, Rissanen A, et al. Serum antioxidant vitamins and risk of cataract. BMF 1992;305:1392-4.

12 The Italian-American Cataract Study Group. Risk factors for age-related cortical, nuclear, and posterior subcapsular cataracts. Am f Epidemiol 1991;133:541-53.

3 Sperduto RD, Hu TS, Milton RC, et al. The Linxian Cataract Studies. Arch Ophthalmol 1993;111:1246-53.

14 Kahn HA, Leibowitz HM, Ganley JP, et al. The Framingham eye study. I. Outline and major prevalence findings. Am f Epidemiol 1977;106:33-41.

15 Ames BN, Shigenaga MK, Hagen TM. Oxidants, antioxidants, and the degenerative diseqases of aging. Proc Natl Acad Sci 1993;90:7915-22.

16 Halliwell B, Gutteridge JMC. Free radicals in biology and medicine. 2nd ed. Oxford: Clarendon Press, 1989.

17 The ATBC Cancer Prevention Study Group. The alphatocopherol, beta-carotene lung cancer prevention study: design, methods, participant characteristics, and compliance. Ann Epidemiol 1994;4:1-10.

18 Pietinen P, Hartman AM, Haapa E, et al. Reproducibility and validity of dieatary assessment instruments. I: selfadministered food use questionnaire with a portion size administered food use questionnaire with a portion

19 The Alpha-Tocopherol, Beta Carotene Cancer Prevention Study Group. The effect of vitamin E and beta carotene on the incidence of lung cancer and other cancers in male smokers. N Engl f Med 1994;330:1029-35.

20 Kalbfleisch JD, Prentice RL. The statistical analysis of future time data. New York: John Wiley, 1980.

21 Breslow NE, Day NE. Statistical methods in cancer research. Vol 2. The design and analysis of cohort studies. (IARC scientific publications no 82). Lyon, France: International Agency for Research on Cancer, 1987.

22 Hankinson SE, Willett WC, Colditz GA, et al. A prospective study of cigarette smoking and risk of cataract surgery in women. $\mathcal{F} A M A$ 1992;268:994-8.

23 Leske MC, Chylack LT Jr, Wu S. The Lens Opacities CaseControl Study Group. The Lens Opacities Case-Control Study: Risk factors for cataract. Arch Ophthalmol 1991;109: 244-51.

24 Ritter LL, Klein BEK, Klein R, et al. Alcohol use and lens opacities in the Beaver Dam Eye Study. Arch Ophthalmol 1993;111:113-17.

25 Christen WG, Manson JE, Seddon JM, et al. A prospective study of cigarette smoking and risk of cataract in men. 7AMA 1992;268:989-93.

26 Heliovaara M, Reunanen A, Aromaa A, et al. Validity of hospital discharge data in a prospective epidemiological study of stroke and myocardial infarction. Acta Med Scand 1984; 216:309-15.

27 Poikolainen K. Accuracy of hospital discharge data: five alcohol-related diseases. Drug Alcohol Depend 1983;12: 315-22

28 Teikari JM, Raivio I. Validity of hospital discharge registry in acute glaucoma. Acta Ophthalmol 1987;65:589-90.

29 Magno BV, Datiles MB, Lasa MS. Progression of lens opacities in cataract patients after one year. Acta Ophthalmol Scand 1995;73:45-9. 